\title{
SUJEITO E POLÍTICA NO DEBATE CONTEMPORÂNEO ${ }^{1}$
}

\author{
SUBJECT Y AND POLITICS IN THE CONTEMPORARY DEBATE \\ SUJETO Y LA POLÍTICA EN EL DEBATE CONTEMPORÁNEO
}

\author{
Aparecida Rosângela Silveira* \\ Cornelis Johannesvan Stralen**
}

\begin{abstract}
RESUMO
Este artigo discute o sujeito político a partir da noção do reconhecimento. São reunidas diferentes concepções teóricas de lógicas de reconhecimento que buscam a compreensão sobre a construção de sujeitos, identidades e da política como práxis humana. As teorias revisitadas contribuem para a construção da noção de sujeito político singular e ativo na busca por transformação e justiça social em contextos de conflitos e de lutas por reconhecimento de diferenças e desigualdades.
\end{abstract}

Palavras-chave: Sujeito. Política. Reconhecimento. Contemporaneidade.

\begin{abstract}
This article discusses the political subject from the notion of reconnaissance. Here we show different theoretical conceptions of logical reconnaissance that seek the understanding of the building of subjects, identities and politics as human praxis. The revisited theories contribute to the construction of the concept of unique and active political subject in the search for changing and social justice in contexts of conflicts and struggles for reconnaissance of differences and inequalities.
\end{abstract}

Keywords: subject. Politics. Reconnaissance. Contemporaneity.

\section{RESUMEN}

Este artículo discute el sujeto político a partir de la noción del reconocimiento. Se reúnen diferentes concepciones teóricas de lógicas de reconocimiento que buscan la comprensión sobre la construcción de sujetos, identidades

Texto recebido em novembro 2013 e aprovado para publicação em setembro de 2014 .

1 Apoio financeiro: Fundação de Amparo à Pesquisa de Minas Gerais. Programa de Capacitação de Recursos Humanos (PCRH 91408/10 - FAPEMIG)

* Mestre em Saúde Pública. Doutoranda do Programa de Pós-Graduação em Psicologia da Universidade Federal de Minas Gerais. Docente do Departamento de Saúde Mental e Saúde Coletiva. Universidade Estadual de Montes Claros - UNIMONTES. Endereço: Av. Dr. Rui Braga, s/n, Vila Mauricéia, CEP 39401-089, Montes Claros, MG, Br. E-mail: silveira.rosangela@uol. com.br

** Doutor em Ciências Sociais. Docente da Faculdade de Filosofia e Ciências Humanas. Programa de Pós-Graduação em Psicologia. Universidade Federal de Minas Gerais - UFMG.Endereço: Av. Presidente Antônio Carlos, 6627, Pampulha, CEP 31270-901, Belo Horizonte, MG, Br. E- mail: stralen@superig.com.br 
y de la política como práctica humana. Las teorías revisitadas contribuyen para la construcción de la noción del sujeto político singular y activo en la búsqueda por la transformación y la justicia social en contextos de conflictos y de luchas por el reconocimiento de las diferencias y las desigualdades.

Palabras clave: Sujeto. Política. Reconocimiento. Contemporaneidad.

ste artigo pretende colocar em evidência a constituição do sujeito político tomado como permanente construção a partir das interações e laços sociais inseridos em lógicas de reconhecimento e contingências. Indaga-se, nessa direção, se o tornar-se sujeito político é uma política do sujeito, ou se se trata de encontros entre sujeitos singulares, causados por modos de ser, que se aproximam e se inserem em determinados espaços de interação social; que vivenciam experiências e conflitos a partir de relações de poder instituídas e desenvolvem interpretações de acontecimentos que, em última instância, lhes configuram identidades, tendo no reconhecimento do outro a sua principal matriz.

Como para o termo sujeito emprega-se uma polissemia de significados, que ora se manifesta como indivíduo autônomo, vivenciando interaçôes e trocas, ora como instância que tem atributos, qualidades e determinantes, neste artigo ele será tomado em seu sentido estrito, do latim subjectus, posto debaixo, reduzido à sujeição, portanto, o ser humano submetido ao social e à linguagem, articulado ao proposto por Fleury (2009), como construção histórica produzida pela tensão entre busca de autonomia e sujeição ao social inerradicável. Trata-se, portanto, do sujeito em sua dimensão de singularidade, tendo uma identidade específica como forma de representação sobre si mesmo, que é construída historicamente a partir de vivências e experiências que realiza em relação ao mundo, por meio de relações de reconhecimento.

Por sua vez, a política será abordada como uma práxis humana tendo como referência a dimensão do antagonismo inerente às relaçōes humanas. Tratase, portanto, de uma forma de busca de superação de impasses decorrentes da impossibilidade de instituir uma vida em coletividade que atenda aos anseios de todos, uma vez que a coexistência humana é marcada pelo conflito (Mouffe, 1996).

Buscando uma articulação entre sujeito e política, o artigo recorre a teóricos que abordam a perspectiva do reconhecimento para compreensão da formação de sujeitos e fenômenos sociais. 


\section{LÓGICAS DO RECONHECIMENTO REVISITADAS}

O termo reconhecimento foi utilizado por Hegel (1770-1831) para descrever as distintas formas de ação recíproca entre os indivíduos que emergem do processo de relaçôes intersubjetivas, estabelecidas nas primeiras experiências do contexto familiar e na vida em sociedade. Para ele, o reconhecimento é a condição para a socialização do ser humano.

No processo de elaboração do Sistema de Eticidade (1802-1803), recorre ao conceito de reconhecimento, de seu contemporâneo Fichte (1762-1814), como ação recíproca entre os indivíduos, constituinte da consciência comum, para propor que as relações éticas de uma sociedade são formas de intersubjetividade prática em que vínculo e comunidade são assegurados por meio do movimento de reconhecimento recíproco. A formação do sujeito do reconhecimento em Hegel compreende três etapas de reconhecimento recíproco: afastamento dos sujeitos das determinações naturais e estabelecimento de relações de reconhecimento recíproco na família; deslocamento das relações familiares para grupos ampliados com pretensôes de direito universal e integração de reconhecimento cognitivo, afetivo e comunicativo para formação de comunidades éticas (Hegel, 1991).

Para ele, o reconhecimento recíproco implica exigências de mais individualidade, gerando um processo contínuo de movimentos de reconciliação e de conflito, que estabelece uma tensão interna estrutural na vida social. A luta pelo reconhecimento é gerada pelas perturbações no convívio social que emergem em formas de conflitos entre sujeitos juridicamente capazes, ao vivenciarem impasses entre suas vontades e o pertencimento a uma comunidade social. A formação de conflito, por sua vez, impulsiona para uma nova etapa de reconhecimento da própria identidade e do reconhecimento intersubjetivo da individualidade humana.

Posteriormente, ele concebe a constituição da coletividade a partir da formação do espírito, que leva o sujeito a se perceber como unidade imediata de singularidade e universalidade. Atribui à formação da consciência humana três momentos distintos: a relação do indivíduo consigo mesmo (cognitivo); as relações institucionalizadas dos sujeitos entre si, permitindo o consenso normativo mínimo para a vida em sociedade por meio do contrato social (subjetivo) e as relaçóes reflexivas dos sujeitos socializados em que a realidade social é um processo de realização do direito (abstrato). Promove, assim, um deslocamento do conflito intersubjetivo para o interior do espírito humano, que força os sujeitos a se reconhecerem mutuamente para formação de uma consciência universal e absoluta, condição para socialização humana. Porém, permanece nesse desdobramento teórico a luta pelo reconhecimento como meio de atingir a universalização do social. 
Assim, o sujeito hegeliano é o sujeito do reconhecimento, que deverá ultrapassar a si mesmo para atingir um saber absoluto sobre si e o mundo, a autoconsciência e a identidade. Portanto, é o sujeito do reconhecimento recíproco, da particularidade sempre individual, marcado pelo conflito entre pretensões de subjetividade e integridade e exigências de respeito ao outro. Em sua concepção de autodeterminação, ser sujeito é ser livre, é necessidade de realização da liberdade enquanto necessidade de realização do espírito. No entanto, para agir eticamente, deve reprimir em si seus desejos e inclinações.

Uma relação propriamente dita entre sujeito e política não está plenamente desenvolvida no jovem Hegel como estará em escritos posteriores. No entanto, através de seu Sistema de Eticidade, apreende-se que o sujeito político em Hegel é o sujeito capaz de romper com a atomização do individualismo, para alcançar uma eticidade que tem na realização do Estado o reconhecimento recíproco entre os sujeitos em sua forma mais abstrata.

Mead (1863-1931) foi leitor de Hegel e influenciado por ele ao construir uma teoria da ação através da construção de relaçôes sociais em que experiência de reconhecimento intersubjetivo conduz à formação da identidade pelo sujeito. Para ele, o indivíduo tem origem no social e é através de processos de sociabilidade que se dá a sua emergência (Mead, 1993).

Sua tese é que tanto o desenvolvimento do indivíduo quanto da consciência de si se realizam no campo da experiência e da conduta, dependendo do grupo social a que pertence e somente na relação com o outro o sujeito pode encontrar significados intersubjetivos para suas ações. É a partir dos significados que lhe são atribuídos por esse outro que o sujeito apreende uma significação para suas ações.

Mead imprime uma perspectiva excêntrica do sujeito em sua teoria de construção da identidade e no processo de formação da consciência de si. Ao atribuir-lhe a capacidade de apreender o significado que suas ações têm para o outro generalizado, vindo do social e instituído nele, o sujeito é colocado como objeto social das ações desse outro e nessa condição realiza a experiência subjetiva, o self, que emerge da experiência de interação e da sua própria ação simbolicamente representada. Nessa perspectiva, o self surge no transcorrer das relações sociais, ele advém da comunicação significativa do encontro do indivíduo com o outro e representa a possibilidade de socialização do sujeito e sua afirmação no contexto coletivo.

O sujeito meadiano é aquele que, a partir de seu processo de socialização e individuação, atingiu a capacidade abstrata de participar nas interações de seu meio social através de relações de reconhecimento intersubjetivo. É um sujeito social, linguisticamente constituído pela mediação do outro. 
Assim, o sujeito político meadiano é o sujeito capaz de ampliar as relações de reconhecimento mútuo articuladas às possibilidades de autonomia e cooperação. É um sujeito que tem a capacidade de desenvolver, a partir da vida comunitária, uma reflexão sobre os anseios de seu grupo de pertencimento e uma ação crítica, com intensificação da discussão política da qual possam emergir soluções construtivas para os problemas sociais. Nesse contexto, uma luta pelo reconhecimento, tal como em Hegel, encontra-se subjacente.

Habermas (1990), aproximando-se de Hegel, afirma que a individualidade se forma a partir do reconhecimento intersubjetivo, promovendo, por meio de interações mediadas simbolicamente, a constituição histórica de vida consciente. Ele empreende a tarefa de compreender a individuação como um processo linguisticamente mediado da socialização. Para ele, entendimento linguístico e entendimento intrassubjetivo histórico são as condições para a individuação social, para a formação de identidades singulares e crescimento da autonomia pessoal.

Sob o paradigma da comunicação, a linguagem é reconhecida por Habermas como forma de integração social que assume significado e validez em uma comunidade linguística. Introduz o conceito do "agir comunicativo" para integrar essas duas concepçóes aos atos de fala que geram processos de entendimento e que, em última instância, conduzem ao reconhecimento intersubjetivo e ao estabelecimento de consensos (Habermas, 1990).

$\mathrm{O}$ agir comunicativo implica lógicas de reconhecimento, assimetrias entre sujeitos e disposição ao diálogo. Também está inserido no mundo da vida, solo da prática comunicativa, em que estão reunidos saber do mundo e saber da linguagem: "O mundo da vida estrutura-se através de tradiçôes culturais, de ordens institucionais e de identidades criadas através de processos de socialização" (Habermas, 1990, p. 100).

Assim, o sujeito habermasiano habita a linguagem inserida socialmente e culturalmente e, por meio do agir comunicativo, atingiu competência interativa, cognitiva e argumentativa para gerar processos de entendimento e estabelecer relaçóes de reconhecimento recíproco que lhe conferem uma identidade. Depreende-se dessa concepção que o sujeito plenamente socializado é, em sua essência, um sujeito político, porque ele atingiu a capacidade de atuar com racionalidade comunicativa em espaços institucionalizados para suplantar interesses particulares e de grupos específicos em direção à formação da vontade e do Estado de direito. 


\section{LÓGICAS DE RECONHECIMENTO E DEBATE ATUAL}

A sociedade pós-moderna vivencia transformações com implicações nas relações sociais e repercussóes sobre os sujeitos diante de conflitos e impasses gerados pelo mal-estar entre grupos hegemônicos, minorias e culturas. Tal movimento tem produzido a formação de novos sujeitos políticos que se manifestam como diferenças, sejam étnicas, linguísticas, culturais ou religiosas, e têm exigido novas políticas que contemplem formas de identidades coletivas apoiadas em expressões de diferenças (Benhabib, 1996).

Nesse contexto se inserem concepções de sujeitos com novas identidades políticas reconhecidas na alteridade, heterogeneidade, dissonância e resistência. Mouffe (2005), partindo da concepção de que o pluralismo de sujeitos, escolhas individuais, concepçôes diferentes do bem tanto quanto culturas, regimes e formas de vida coletiva implicam transformações de ordem simbólica nas relações sociais, afirma que antagonismo e conflito são constitutivos e estão presentes na vida política que vivencia tensão entre lógicas de identidade e de diferença. Para ela, somente as oportunidades de participação expressam as diferenças de indivíduos e grupos e permitem o reconhecimento dos sujeitos e da divisão irredutível entre eles.

Essa perspectiva afasta o ideal do bem comum e privilegia novas relações sociais com possibilidade de discursos, práticas e jogos de linguagem e pluralidade de valores que produzem sujeitos posicionados democraticamente.

Nessa direção, Young (2011) critica formas de interpretação de grupos que se reduzem apenas a identidades. Para a autora, os grupos sociais se constituem a partir de um coletivo de pessoas que se diferenciam de outros grupos em termos de cultura, práticas, formas de vida e experiências. Assim, os grupos constituem os sujeitos, que com suas histórias, afinidades e afastamentos se diferenciam no seu grupo e nos demais.

Portanto, o sujeito emerge do grupo que partilha experiências, porém traz marcas estruturais singulares: "sujeitos individuais constroem suas próprias identidades, mas não sob condições que foram escolhidas por eles" (Young, 2000, p. 99). Nesse sentido, a identidade do sujeito não é apenas somatório de afinidades; ela se constrói pela maneira como o sujeito lida e age em relação a outras posições no grupo social. E sua identidade política se constrói também em contextos de grupos sociais com reconhecimento e inclusão das diferenças de sujeitos que atuam em busca da transformação de expressões de interesses particulares e de grupos em reivindicaçôes de justiça.

Taylor, em seu ensaio A politica do reconhecimento (1994), destaca o conceito de reconhecimento para uma análise dos atuais conflitos culturais, étnicos, 
religiosos e de minorias. Para o autor, a construção de identidades é em parte atribuída pela presença ou ausência de formas de reconhecimento, que podem também apresentar formas distorcidas das realidades dos sujeitos (Taylor, 1994).

Tendo como referência o multiculturalismo como teoria normativa para enfrentamento de conflitos decorrentes da convivência entre sujeitos e diferentes grupos, Taylor propõe uma política do reconhecimento das diferenças pelo Estado, em defesa das sociedades culturais que são espaços de formação de identidades, conjugando direitos individuais e coletivos. Ele critica Habermas, que fixa a teoria da ação comunicativa num padrão evolutivo de relações, excluindo as diferentes formas de vida, com empobrecimento da diversidade cultural dos sujeitos que compartilham língua, história e cultura comuns.

A política do reconhecimento propõe o reconhecimento universal das identidades singulares pela via da diferença, atrelando uma noção de cidadania para além do reconhecimento de igualdades, pautada no respeito à diferença, apontando para o caráter dialógico entre identidade e reconhecimento para formação do sujeito, que ocorre na interação com o outro em contextos linguísticos, sejam sujeitos individuais ou coletivos. Nessa perspectiva, o sujeito político é aquele que, reconhecido em sua diferença e singularidade, exerce sua participação cidadã em contextos públicos na defesa de direitos das particularidades das diferenças culturais e de minorias.

Por sua vez, Honneth (2003), em Luta pelo Reconhecimento, faz uma retomada dos escritos do jovem Hegel e de Mead, com quem compartilha a noção de reconhecimento intersubjetivo, para destacar os aspectos da interação social e do conflito como constitutivos das identidades individuais e coletivas dos sujeitos. Em sua teoria crítica, põe no centro de suas investigações as categorias conflito e reconhecimento, destacando a luta pelo reconhecimento como fundamento normativo e condição para os sujeitos se conscientizarem de suas próprias identidades e serem reconhecidos individual e socialmente por meio de sucessivas etapas de reconciliação e conflito.

Honneth (2003) apresenta um quadro interpretativo das estruturas das relações sociais de reconhecimento identificadas como dedicação emotiva, respeito cognitivo e estima social, expressos nas formas de amor e amizade, direitos e solidariedade que promovem relações de autoconfiança, autorrespeito e autoestima. Por sua vez, as formas de desrespeito, como maus-tratos e violação, privação de direitos, exclusão, degradação e ofensa podem se constituir em ameaças à integridade física, à integridade social e à honra e dignidade, constituindo-se esses elementos as chaves para a emergência dos conflitos sociais. As três formas de reconhecimento promovem as condições sociais para que os 
sujeitos possam atingir uma atitude positiva para com eles mesmos e para com os outros e se tornarem autônomos, individualizados e identificados com seus objetivos e desejos.

Assim, Honneth afirma que o reconhecimento é alcançado pelos sujeitos singulares e grupos através da luta: "uma luta por reconhecimento que, como força moral, promove desenvolvimentos e progressos na realidade da vida social do ser humano" (Honneth, 2003, p. 227). Nesse sentido, a reconstrução de processos evolutivos da sociedade moderna só pode ser consolidada considerando-se processos dinâmicos e contingentes por meio de pretensões de reconhecimento. Para ele, são as relações de reconhecimento que conduzem à formação de identidades dos sujeitos e grupos sociais, tendo em sua matriz os conflitos. Assim, ele estabelece um distanciamento da teoria da ação comunicativa habermasiana com predomínio da razão instrumental. Para ele, a concepção de autonomia do sujeito está ligada a condições intersubjetivas de reconhecimento a partir da interação social e da formação de conflitos, enquanto que, para Habermas (1990), a autonomia do sujeito é a realização de competências comunicativas para formação de entendimento e consenso.

$\mathrm{Na}$ perspectiva de Honneth (2003), o sujeito político emerge de uma comunidade de valores, através do compartilhamento de significados e da valorização de suas singularidades, atingindo seu maior grau de eticidade pelo reconhecimento intersubjetivo das diferenças.

Ainda dentro do campo teórico da teoria crítica, Fraser, ao aprofundar os temas da redistribuição e da igualdade para tratar das disparidades sociais e políticas a que os sujeitos se encontram submetidos, propõe o debate sobre políticas redistributivas e lutas pelo reconhecimento social como respostas sociais para projetos emancipatórios. Sua concepção de justiça social integra redistribuição e reconhecimento de diferenças e desigualdades como formas de inclusão social, para além da igualdade perante a lei e de oportunidades.

Isso requer a promoção de arranjos sociais que impliquem a participação de todos como pares na vida social: "Superar a injustiça significa desmantelar os obstáculos institucionalizados que impedem alguns sujeitos de participarem, em condições de paridade com os demais, como parceiros integrais da interação social" (Frazer, 2009, p. 17).

Para Fraser, há uma insuficiência política da teoria do reconhecimento de Honneth, por se afastar dos movimentos sociais, que se constituem em espaços políticos privilegiados de lutas pelo reconhecimento das diferenças e de construção de políticas culturais e de identidade das quais emergem novos sujeitos na vida política. 
Ainda em torno da noção do reconhecimento é possível estabelecer um diálogo entre concepções teóricas da teoria social e da democracia radical com a psicanálise. Tal como no pensamento hegeliano, a psicanálise afirma que o processo de constituição do sujeito se dá através de relações de reconhecimento e a partir do afastamento do ser humano de determinações naturais, assumindo que sua sobrevivência está subordinada à sua relação com o outro social que $o$ reconhece em seu desejo de cuidar, face ao desamparo inicial na vida, e por essa via promove a possibilidade de sua existência.

Freud estabelece na relação entre vivência de desamparo e dependência do outro a matriz para o desenvolvimento do ser humano, da vida psíquica e do processo civilizatório, estabelecendo uma "educação para a realidade" (Freud, 1927/1975, p. 63-64). Contudo, admite posteriormente a impossibilidade de o sujeito proteger-se de todos os riscos inerentes ao processo civilizatório e à própria vida, apontando que algo do desamparo permanece inerradicável na condição humana e se expressa na forma de conflitos (Freud, 1927).

Nessa mesma direção, encontra-se em Lacan (1984) a importância das primeiras relações dentro do grupo familiar para a constituição do sujeito. Para além do biológico e do numérico, a família, para ele, "desempenha um papel primordial na transmissão da cultura” (p.13), por meio da primeira educação, da repressão de instintos e na aquisição da linguagem. Entretanto, sua ênfase recai na noção de complexo de desmame como regulação cultural, reconhecido por ele como experiência que fixa no psiquismo a forma primordial da imago materna fundamental para que o sujeito se reconheça e possa introduzir-se no grupo social. Aproxima-se de Hegel, ao afirmar que o sujeito deverá imprimir no curso de sua vida, como processos similares a complexos de desmames, uma luta permanente pelo reconhecimento fora do grupo familiar.

Para a psicanálise, no início da vida, o sujeito não tem a ideia de unicidade; somente pela via da incidência do outro cuidador no seu corpo, por meio de um desejo particularizado, lhe serão inscritas marcas que constituirão seu corpo pulsional e a experiência da falta do outro. A resposta que vem do sujeito é sempre singular; estabelece a forma como cada um apreende o que vem do outro e o modo de se relacionar com os diversos objetos nas etapas sucessivas de desenvolvimento que implicam em experiências de perdas, conflitos e formação de identidades.

O papel das primeiras relações do sujeito como etapa fundamental para seu processo de socialização e construção de identidades levou Honneth à aproximação de Winnicott, que compreende a relação mãe e filho como intersubjetividade e inicialmente indiferenciada; uma simbiose que deverá 
ser desfeita por meio da cooperação de ambos para atingir o processo de amadurecimento infantil e construção da autonomia. Uma leitura psicanalítica de orientação lacaniana aponta para a organização da relação mãe e filho por meio de uma falta que não consegue ser totalmente simbolizada, restando ao sujeito, para seu amadurecimento e busca de autonomia, lidar com uma falta estrutural que introduz a dimensão do desejo e do mal-entendido. É por essa via do reconhecimento que o sujeito se diferencia em busca de autonomia, permanecendo um resto não simbolizado como mal-estar frente ao desamparo inicial que não se recobre, restando ao sujeito, no percurso de sua vida, encontrar saídas para lidar com o que lhe falta; uma delas seria a inserção em comunidades políticas.

Laclau e Mouffe (2015), ao reconhecerem o antagonismo como dimensão ontológica do sujeito e do social, aproximam-se do caráter irredutível do malestar estrutural na cultura apontado por Freud, com a presença da pulsão de morte. Também se aproximam do debate psicanalítico quando apontam para a presença de significantes vazios na cultura como faltas que introduzem os sujeitos em relações de equivalência. Contudo, o laço social sempre implica em problema político que não tem como ser solucionado em sua plenitude, sempre restando desacordos e mal-entendidos. O laço social que não reconhece esse limite promove a irrupção de formas de violência que podem ser mortíferas na medida em que não conseguem ser inscritas no jogo simbólico (Alemán, 2009).

A teoria social e a teoria psicanalítica reconhecem a importância do laço social na constituição do sujeito, nas formas de interação da vida social e na relação com a política. O desamparo inicial como condição humana fundante, a importância da interação entre criança e cuidador para seu desenvolvimento e inserção numa comunidade linguística e a constituição de uma identidade a partir do outro são elementos presentes nos dois contextos teóricos. Ademais, a condição inerente do conflito do ser humano e a luta pelo reconhecimento são pontos em comum nas suas matrizes teóricas para analisar os conflitos sociais atuais, para compreensão de mecanismos de construção de identidades e reconhecimento das diferenças. Essas teorias também compartilham o caráter singular dos sujeitos que sempre experimentaram inserção e desinserção no social e se servem de acontecimentos que são da ordem da contingência, fazendo com que a política seja um processo contínuo, marcado por encontros e desencontros do sujeito com ele mesmo e com os outros.

Psicanálise e teoria social trabalham por uma política e uma ética que se contrapõem ao discurso de sujeito universal e total. Há divisão, há singularidades, há antagonismos e há conflitos e desacordos nos sujeitos e entre eles. Não existe sociedade sem fraturas, conciliada com ela mesma. Porém, existem projetos 
emancipatórios e processos que podem transformar os modos como sujeitos e sociedades lidam com o que é da ordem do insuportável.

Alemán (2009, p. 23) enfatiza ainda que para a psicanálise o político surge do encontro traumático do sujeito com o real, que não é a realidade construída simbolicamente, e sua captura, embora reconheça que a própria política seja um saber fazer com esse encontro. Assim, a existência do ser falante e os caminhos dos sintomas são formas de inclusão de conceitos da psicanálise no debate sobre o político. Quando os teóricos da teoria social e da democracia radical propõem a noção do sujeito constituído na reivindicação de identidade, pautada na singularidade diante do universal, é possível pensar o sujeito político, também, nas fronteiras do inconsciente.

\section{TORNAR-SE SUJEITO POLÍTICO}

Para concluir, verifica-se que a noção de reconhecimento apresentada por diferentes perspectivas percorre as concepçôes de sujeito com um progressivo deslocamento do universal ao particular, resgatando sua unicidade. Há consenso de que a interação é fator fundamental de socialização e inserção dos sujeitos na linguagem e na cultura. O laço social é enfatizado como forma de construir relações que possam minimizar tensões decorrentes do conflito estrutural inerente à condição humana que se manifesta em forma de antagonismos.

Diante da diversidade de enfoques teóricos, o sujeito político é pensado como um sujeito das relações intersubjetivas, da ação; um sujeito social, da ação comunicativa, da diferença e da identidade. Há um consenso de que sua atuação em contextos sociais e institucionais está pautada pela busca de reconhecimento nos planos individual e coletivo e que são sujeitos voltados para a democratização das relaçôes sociais que desembocam em projetos emancipatórios diante do tensionamento entre relações de antagonismos.

Conclui-se que a noção de reconhecimento estabelece um diálogo entre diferentes concepções teóricas e promove um alargamento da noção de sujeito político como construção permanente em contextos de interação. Permite, ainda, pensar na construção de subjetividades no contexto de relações de poder em que as diferenças não sejam suprimidas. 


\section{REFERÊNCIAS}

Alemàn, J. (2009). Para uma izquierda lacaniana... intervenciones y textos. Buenos Aires: Grama Ediciones.

Benhabib, S. (1996). Democracy and Difference: contesting the boundaries of the political. New Jersey: Princeton University Press.

Fleury, S. (2009). Socialismo e democracia: o lugar do sujeito. In S. Fleury \& L. V. C. Lobato (Orgs.). Participação, democracia e saúde. (pp. 24-26). Rio de Janeiro: CEBES, Coleção Pensar em Saúde).

Fraser, N. (2009). Reenquadrando a justiça em um mundo globalizado. Lua Nova n. 77, 11-39. Recuperado a partir de http://dx.doi.org/10.1590/S010264452009000200001. http://www.scielo.br/scielo

Freud, S. (1927/1975). O futuro de uma ilusão. In Obras Completas (Vol. 21, pp. 62-64). Rio de Janeiro: Imago.

Habermas, J. (1990). Pensamento pós-metafísico: estudos filosóficos. In F. B. Siebeneichler (Trad.). (pp. 77-100). Rio de Janeiro: Tempo Brasileiro.

Hegel, G. W. F. (1991). O sistema da vida ética. In M. Artur (Trad.). Rio de Janeiro: Ediçõos 70.

Honneth, A. (2003). Luta por reconhecimento: a gramática moral dos conflitos sociais. São Paulo: Editora 34.

Lacan, J. (1984). Os Complexos familiares. Rio de Janeiro: Jorge Zahar Editor. (Coleção Campo Freudiano no Brasil).

Laclau, E. \& Mouffe, C. (2015). Hegemonia e estratégia socialista: por uma política democrática radical. São Paulo: Editora Intermeios.

Mead, G. H. (1993). Espiritu, persona y sociedad. Buenos Aires: Paidós.

Mouffe, C. (1996). Democracy, power, and the 'political In S. Benhabib (Ed.). Democracy and difference: contesting the boundaries of the political. New Jersey: Princeton University Press.

Mouffe, C. (2005). The return of political. London / New York: Verso.

Taylor. C. (1994). The politics of recognition. In: A. Gutmann, (Ed.). Multiculturalism: Examining the politics of recognition. (pp. 25-73). Princeton: Princeton University Press. 
Young, I. M. (2000). Inclusion and democracy. Oxford. New York: Oxford University Press.

Young, I. M. (2011). Justice and the politcs of difference. Princeton / New Jersey: Princeton University Press. 